\section{THE LOCO-WEED DISEASE}

For several decades the loco-weed disease has been a subject of much interest both practical and theoretical-practical because it is the cause of extensive losses of live stock in the western half of the United States, theoretical because to the pharmacologist it has offered an unusually puzzling and tantalizing problem which has hitherto baffled all attempts at solution.

By far the most important contribution ever made to the subject has recently appeared as a bulletin of the Bureau of Plant Industry, United States Department of Agriculture, by A. C. Crawford. ${ }^{1}$ In order to appreciate the significance of this piece of work, which is one of the most important contributions to pharmacology ever made in this country, it is necessary to recall the state of knowledge concerning "loco" when Crawford began his investigations. The condition has been known for at least sixty years; the United States Department of Agriculture began to investigate it in 1873 and has returned to the problem at frequent intervals since. In addition it has been the subject of study by a number of state institutions and by many private individuals. The condition has usually been ascribed to the eating of certain plants; most commonly various species of Aragallus and Astragalus were held responsible for it. All efforts to obtain a poisonous substance from these plants had, however, failed. Most experimentors had been unable to produce any poisonous effects whatever, when the plants or their extracts were administered to animals; Professor Sayre stated that he had sent thousands of pounds of the dried plants to various investigators in America and Europe, but all reports were negative as to pharmacological activity. The condition was ascribed by some to the mechanical action of fine hairs on the plant, by others to bacteria associated with the plants; others denied any causal relation between the plant and the condition and attributed the latter to malnutrition, helminthiasis, etc.

1 "Barium, A Cause of the Loco-weed Disease," Bull. 129, Bureau of Plant Industry.
The fow who had seen poisonous effects from the plants seemed inclined to the belief that a poisonous substance was actually present, but that it was too unstable to admit of isolation except under the most favorable conditions of work.

Thus when Crawford began his work in 1905 it was still a matter of controversy whether the plants he was to study were poisonous or not. Field experiments carried out independently by C. D. Marsh and laboratory experiments by Crawford soon showed definitely that it is possible to produce sickness and death by the administration of certain of the plants. The first step having been thus taken, Crawford attacked the problem of the nature of the poisonous substance. Seldom has a pharmacologist been confronted with a more difficult problem; the few clues from the work of the last twentyfive years proved absolutely misleading. It is impossible to give the details, but a brief outline will indicate what an amount of the most painstaking work was necessary before success was finally achieved. Having determined the amount of plant necessary to kill a rabbit of a certain weight, Crawford proceeded to the chemical examination controlling each step by experiments on animals. One group of poisons after another-volatile poisons, alkaloids, glucosides, organic acids, toxalbuminswere excluded. The first encouragement came when it was found that the toxicity was not destroyed by boiling. This was followed by the surprising discovery that the ash of the plant was poisonous; if any conclusion was to be drawn from the work of previous writers it was that the poisonous substance-if such were present at all-was so unstable that it did not withstand even drying!

After the discovery that the ash was toxic there were still many difficulties. The ash was very complex but Crawford systematically separated it into many fractions, testing each physiologically. In this way all of the common heavy metals were excluded; the ash however, contained small amounts of zirconium, titanium, etc. All of these as well as beryllium, thorium, thallium, had to be 
excluded by various chemical and physiological tests. Search was also made for a radio-active substance. Chemists had called attention to the abundance of calcium in the ash; this and strontium were excluded from being the toxic agents.

Finally Crawford noticed that extracts prepared with sulphuric acid were inactive; further, that active extracts caused a rise of blood-pressure. Both of these observations suggested the presence of barium. After a long series of careful experiments the author reached the following conclusions:

A close analogy exists between the clinical symptoms and pathological findings in barium poisoning and those resulting from feeding extracts of certain loco plants. Small doses of barium salts may be administered to rabbits without apparent effect, but suddenly acute symptoms set in analogous to what is reported on the range.

Finally barium was found in the ash of many "loco" plants in amounts sufficient to account for the symptoms.

Among the other important conclusions, some of which help to explain the unsatisfactory results of former workers, are the following:

Loco plants grown on certain soils are inactive pharmacologically and contain no barium. In drying certain loco plants the barium apparently is rendered insoluble so that it is not extracted by water, but can usually be extracted by digestion with the digestive ferments.

The barium to be harmful must be in such a form as to be dissolved out by digestion.

In deciding whether plants are poisonous it is desirable not merely to test the aqueous or alcoholic extract, but also the extracts obtained by digesting these plants with the ferments which occur in the gastro-intestinal tract.

These experiments afford another illustration of how indispensable are animal experiments in all kinds of pharmacological work.

The author conservatively limits his conclusions to the plants he has studied, and recognized that in the plants grown in other localities the toxic action may be due to substances other than barium.

There is an extraordinarily rich and wellselected bibliography of the entire subject of "loco" and also of barium poisoning in both man and the domestic animals.

It seldom falls to the lot of an investigator to carry to such a successful conclusion a problem of such complexity and so baffling; it will long remain as one of the most notable contributions to pharmacology made here or abroad. Reid Hunt

Hygiento Laboratory, WASHINGTON, D. C.

\section{SPECIAL ARTICLES}

THE EFFECT OF LESIONS OF THE DORSAL NERVE ROOTS ON THE REFLEX EXCITABILITY OF

THE SPINAL CORD (PRELIMINARY NOTE) ${ }^{1}$

IN some preliminary experiments Professor Carlson found that lesions of the dorsal nerve roots appear to have the same effect on the cross reflexes of the spinal cord as transsection of the cord itself. That is, in animals in which the reflexes disappear temporarily after transsection of the cord (spinal shock) the cross reflexes are similarly lost temporarily after lesions of the dorsal nerve roots on one side.

The experiments here reported were undertaken at the suggestion of Professor Carlson in order to determine definitely this parallelism in different animals, because of the important bearing of these results on the theories of spinal shock.

Methods of Experiments.-Section of the dorsal nerve roots to one limb: (a) After high section of the spinal cord, $(b)$ on the intact animal.

In pigeons, cats and dogs after the high section and recovery from shock and anæsthesia (usually one day) the final operation of cutting the dorsal nerve roots was made without anæsthesia.

Results of Experiments. - The effect on the cross reflexes caused by the cutting of the dorsal roots to a limb is as follows: In snapping turtles, loss of cross reflexes for 5-10 minutes; in frogs, loss of cross reflexes for 15-30 minutes; in pigeons, no loss of reflexes;

${ }^{1}$ From the Hull Laboratory of Physiology, University of Chicago. 